\title{
SUBLINGUAL DERMOID CYST
}

\author{
Ghulam Ali Memon, Afzal Junejo and Fazila Hashmi
}

\begin{abstract}
A case of 22 years old male with a sub lingual swelling causing discomfort in deglutition and speech is reported. The pathology was diagnosed as sub lingual dermoid cyst. It was completely excised from an oral approach. Later, the normal functions of tongue were restored without any residual complaint.
\end{abstract}

KEY WORDS: Sub lingual Dermoid Cyst. Swelling. Management. Pathology.

\section{INTRODUCTION}

During the development of head and neck as the process of fusion completes, a small piece of epidermis may get entrapped deep in the mid line, just behind the jaw and later forms a sublingual dermoid cyst. ${ }^{1}$ The term dermoid cyst clinically refers to describe three different lesions and includes epidermoid cyst, dermoid cyst and teratoid cyst. Though considered to be developmental anomaly, these cysts can also occur following some surgical procedure causing minor trauma to the oral cavity in early period of life. ${ }^{2}$ These cysts are rarely reported but still should be differentially diagnosed from common pathologies like ranula, thyroglossal cysts, bilateral and unilateral blockade of Wharton's duct and cystic hygroma.

\section{CASE REPORT}

A 22 years old male, nurse by profession, reported to outpatients surgical department of Liaquat University Hospital, with a year long history of swelling in the floor of mouth. The swelling started insidiously, followed a slow pattern of progression and attained the presenting size. The patient experienced difficulty in swallowing and speech due to impaired movements of tongue. A local general practitioner tried to aspirate fluid from it, which resulted in temporary reduction in the size of swelling. Examination showed a distinct swelling in the sub mental region, giving the patient's face a double chin appearance. Oral cavity, clinically, revealed a raised tongue due to underlying swelling. Due to its location, it was not possible to assess the size of it. The swelling was non-tender, soft to firm and immobile, with normal overlying mucosa, which was quite easy to be pinched off. The swelling did not fluctuate, neither it did transilluminate. The regional lymph nodes were not palpable. The provisional diagnosis of sublingual dermoid cyst was made and patient was admitted in the ward. The swelling was excised via the oral route by an incision, which extended from the tip of under surface of tongue upto the lingual frenulum. Being superficial to mylohyoid muscle, it was possible to enucleate the cyst completely via this approach. The wound was closed using 3/0 vicryl. The size of cyst turned out to be $6 \times 4 \mathrm{cms}$. The histopathology report of biopsy confirmed the provisional diagnosis of dermoid cyst by showing the presence of cheesy keratin material in the cavity in which hair were dispersed. The cyst wall was lined with keratinized stratified squamous epithelium. The post-operative recovery was uneventful and patient went home on third postoperative day without any residual illness. Patient came after a period of one month for follow up visit and had no more complaints.

\section{FIGURE I: POST-OPERATIVE SPECIMEN OF CYST}

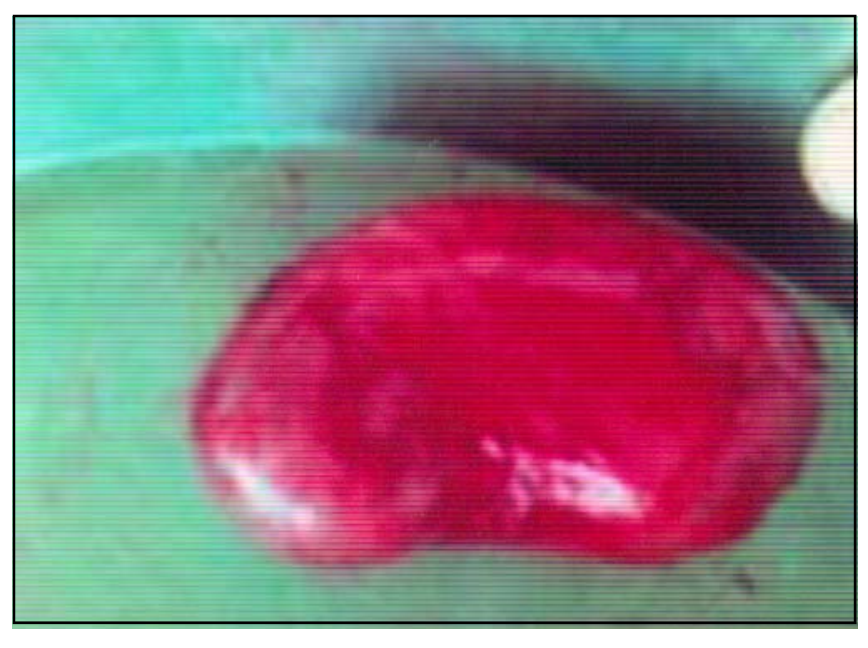

\section{DISCUSSION}

The term dermoid cyst does not appear to be restricted to a single kind of lesion, nor is it used in only a single medical discipline. For example, to a gynaecologist the term dermoid cyst is a tumor associated with ovary, while a neurosurgeon would say that a dermoid cyst is a congenital anomaly associated with spine and cranium. But for general surgeons, pediatricians and dermatologists dermoid cyst means subcutaneous cysts, which are usually congenital. These 
cysts are uncommon in the head and neck region and are rare in the floor of the mouth. They may occur at other sites like palate, nose, tongue and in extremely rare cases within the Eustachian tube. The incidence mentioned in the international literature is 1.6 to $6.9 \%$, and they represent less than $0.01 \%$ of all oral cavity cysts. ${ }^{4}$ However, national literature reports just one case. ${ }^{5}$ These lesions are classified under heading of cystic teratoma and usually are discovered at an age group, which ranges from 18-30 years without any predilection to either sex. These cysts are rarely seen in infancy and prenatal diagnosis can be made using ultrasound, which should be completed with a puncture procedure to prevent complication like polyhydroamnios. 6 These cysts clinically present as supramylohyoid and inframylohyoid depending upon their relevance with mylohyoid muscle. Different surgical techniques can be used according to size and variety of the lesion and include a transcutaneous approach for median geniohyoid cysts, an extended median glossotomy technique for very large median genioglossal cysts, a median glossotomy technique for median genioglossal cysts and a midline incision of the oral mucosa along the lingual frenulum for sublingual cysts. ${ }^{7}$ Fine needle aspiration cytology can be an important diagnostic tool in the diagnosis and may also perform an important function in cases where emergency reduction is required. ${ }^{8}$ However, contrast CT scan and MRI remain to be the gold standard for diagnosis. ${ }^{9}$ These cysts can also get infected and may present with a discharging sinus in the sub mental region. In prolonged cases, there is a chance of malignant changes in these cysts though just one case has been reported world wide. ${ }^{10}$

\section{REFERENCES}

1. Browse NL. An introduction to the symptoms and signs of surgical diseases. Third ed. London: Arnold. 1997; Pp. 249-50.

2. De Ponte FS, Brunelli A, Marchetti E, Bottini DJ. Sublingual epidermoid cyst. J Craniofac Surg. 2002; 13(2):308-10.

3. Worthington JP, Sinclair JH. Median dermoid cyst. N Z Dent J. 1992; 88 (391):17-9.

4. Ege G, Akman H, Senvar A, Kuzucu K. Case report: Sublingual dermoid cyst. Tani Girisim Radyol. 2003; 9(1):57-9. [Article in Turkish]

5. Din SU. Dermoid cyst of the floor of mouth. J Coll of Physicians Surg Pak. 2003;416-7.

6. Polak P, Santavy J, Micanik B, Hyianek J, Burmog T, Brazda A. An unusual tumor of the oral cavity in a fetus and prenatal ultrasonography--case report. Ceska Gynekol. 2002; 67(3):163-7. [Article in Spanish]

7. Longo F, Maremonti P, Mangone GM, De Maria G, Califano L. Midline (dermoid) cysts of the floor of mouth: report of 16 cases and review of surgical techniques. Plast Reconstr Surg. 2003; 112 (6):1560-5.

8. Babuccu O, Isiksacan Ozen O, Hosnuter M, Kargi $\mathrm{E}$, Babuccu B. The place of fine-needle aspiration in the pre-operative diagnosis of the congenital sublingual teratoid cyst. Diagn Cytopathol. 2003; 29(1):33-7.

9. Kurabayashi T, Ida M, Sasaki T. Differential diagnosis of submandibular cystic lesions by computed tomography. Dentomaxillofac Radiol. 1991;20(1):30-4.

10. Devine JC, Jones DC. Carcinomatous transformation of a sublingual dermoid cyst. A case report. Int J Oral Maxillofac Surg. 2000; 29(2):126.

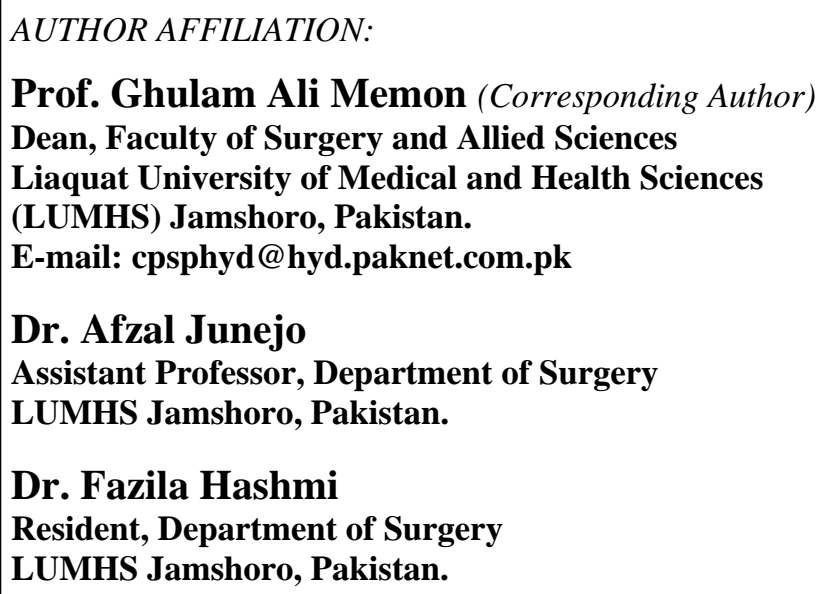

